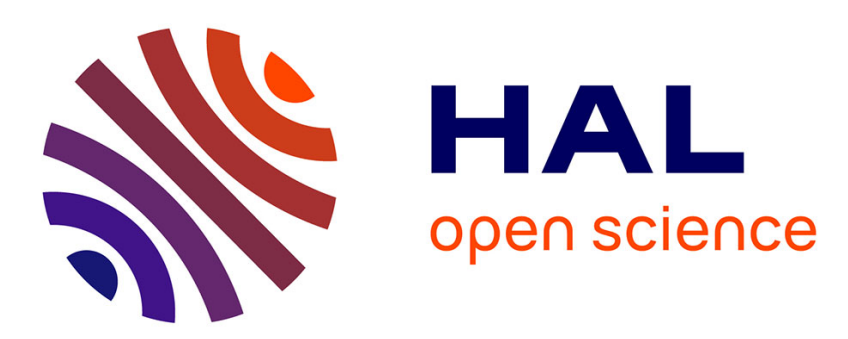

\title{
Soret-driven convection and separation of binary mixtures in a porous horizontal slot submitted to a heat flux
}

Marie-Catherine Charrier-Mojtabi, Bilal Elhajjar, Bafétigué Ouattara, Abdelkader Mojtabi, Pierre Costeseque

\section{To cite this version:}

Marie-Catherine Charrier-Mojtabi, Bilal Elhajjar, Bafétigué Ouattara, Abdelkader Mojtabi, Pierre Costeseque. Soret-driven convection and separation of binary mixtures in a porous horizontal slot submitted to a heat flux. Comptes Rendus Mécanique, 2011, vol. 339, pp. 303-309. 10.1016/j.crme.2011.03.006 . hal-00926373

\section{HAL Id: hal-00926373 https://hal.science/hal-00926373}

Submitted on 9 Jan 2014

HAL is a multi-disciplinary open access archive for the deposit and dissemination of scientific research documents, whether they are published or not. The documents may come from teaching and research institutions in France or abroad, or from public or private research centers.
L'archive ouverte pluridisciplinaire HAL, est destinée au dépôt et à la diffusion de documents scientifiques de niveau recherche, publiés ou non, émanant des établissements d'enseignement et de recherche français ou étrangers, des laboratoires publics ou privés. 




OATAO is an open access repository that collects the work of Toulouse researchers and makes it freely available over the web where possible.

This is an author-deposited version published in : http://oatao.univ-toulouse.fr/ Eprints ID : 10653

To link to this article : DOI: $10.1016 /$ j.crme.2011.03.006

http://dx.doi.org/10.1016/j.crme.2011.03.006

To cite this version : Charrier-Mojtabi, Marie-Catherine and Elhajjar, Bilal and Ouattara, Bafétigué and Mojtabi, Abdelkader and Costeseque, Pierre Soret-driven convection and separation of binary mixtures in a porous horizontal slot submitted to a heat flux. (2011) Comptes Rendus Mecanique, vol. 339 (n 5). pp. 303-309. ISSN 1631-0721

Any correspondance concerning this service should be sent to the repository administrator: staff-oatao@,1istes-diff.inp-toulouse.fr 
Thermodiffusion and coupled phenomena / Thermodiffusion et phénomènes couplés

\section{Soret-driven convection and separation of binary mixtures in a porous horizontal slot submitted to a heat flux}

\section{Convection thermosolutale avec effet Soret : séparation des espèces en couche poreuse horizontale soumise à un flux de chaleur}

Marie Catherine Charrier-Mojtabi ${ }^{c}$, Bilal Elhajjar ${ }^{\mathrm{a}, \mathrm{b}}$, Bafétigué Ouattara ${ }^{\mathrm{a}, \mathrm{b}}$, Abdelkader Mojtabi ${ }^{a, b, *}$, Pierre Costesèque ${ }^{a, b}$

a Université de Toulouse, INPT, UPS, IMFT (Institut de mécanique des fluides de Toulouse), allee Camille-Soula, 31400 Toulouse, France ${ }^{\mathrm{b}}$ CNRS, IMFT, 31400 Toulouse, France

c Université de Toulouse, UPS, Laboratoire Phase, EA 3028, 118, route de Narbonne, 31400 Toulouse, France

Keywords:

Convection

Thermodiffusion

Thermodiffusion

Soret effect

Species separation

\section{Mots-clés:}

Convection

Thermodiffusion

Thermogravitation

Effet Soret

Séparation des espèces
A B S T R A C T

The onset of Soret-driven convection in a shallow porous horizontal layer filled with a binary mixture and submitted to a vertical heat flux on the two horizontal walls is investigated. We study the species separation between the two vertical ends of the cell, which appears for low values of the Rayleigh number and for positive separation ratio. An analytical solution is performed and the separation is expressed in terms of thermal Rayleigh number, Lewis number, separation ratio and aspect ratio of the cell. These analytical results are corroborated by direct non-linear numerical simulations. Then, the results are compared with those obtained in a differentially heated vertical cavity.

\section{R É S U M É}

On étudie la naissance de la convection thermosolutale avec prise en compte de l'effet Soret, dans une couche mince horizontale poreuse remplie d'un mélange binaire et soumise à un flux de chaleur vertical sur ces deux parois horizontales. Pour de faibles valeurs du nombre de Rayleigh et pour des facteurs de séparation positifs, la séparation des espèces entre les deux extrémités verticales de la cellule est déterminée. On développe une solution analytique qui permet d'exprimer la séparation en fonction du nombre de Rayleigh, du nombre de Lewis, du facteur de séparation et du rapport d'aspect de la cellule. Ces résultats analytiques sont corroborés par des simulations numériques directes et comparés avec ceux obtenus en cellule verticale.

\footnotetext{
* Corresponding author at: Université de Toulouse, INPT, UPS, IMFT (Institut de mécanique des fluides de Toulouse), allee Camille-Soula, 31400 Toulouse, France.

E-mail address: mojtabi@imft.fr (A. Mojtabi)
} 


\section{Introduction}

In binary fluid mixtures subjected to temperature gradient, the thermodiffusion effect induces a mass fraction gradient (usually called the Soret effect). In the expression of the mass flux $\boldsymbol{J}$ of one of the components, besides the usual isothermal contribution given by Fick law, there is an additional contribution proportional to the temperature gradient:

$$
\boldsymbol{J}=-\rho D \nabla C-\rho C(1-C) D_{T} \nabla T
$$

where $D$ is the mass-diffusion coefficient, $D_{T}$ is the thermodiffusion coefficient, $\rho$ is the density, and $C$ is the mass fraction of the denser component.

Thermogravitational diffusion is the combination of convection and thermal diffusion. The coupling of these two phenomena may lead to species separation.

In 1938, Clusius and Dickel [1] successfully carried out the separation of gas mixtures in a differentially heated vertical column (TGC). In the following year, two fundamental theoretical and experimental works on species separation of a binary mixture by thermogravitation were published. Furry, Jones and Onsager (1939) [2], (FJO theory) developed the theory of thermodiffusion to explain the experimental process involved in the isotope separation. The theory developed for differentially heated vertical columns showed that there is a maximum separation for an optimal value of the cell thickness which is of the order of a fraction of mm which significantly reduces the amount of separated species. For cells of larger thickness the separation decreases since the flow velocity becomes much higher than the one leading to the maximum separation. Lorenz and Emery (1959) [3] proposed to introduce a porous medium into the cavity. During the last ten years, many works were devoted to the improvement of the experimental device in order to increase separation. Platten et al. (2003) [4] used a tilted cavity heated from the top. Elhajjar et al. (2008) [5] studied the unicellular flow appearing at the onset of convection in a binary fluid saturating a horizontal porous cavity heated from below. If the separation ratio $\psi$ is positive and greater than a certain value $\psi_{\text {mono }}$, it was shown that it is possible to separate the species of the binary fluid mixture between the two ends of the cell. Moreover, the optimal Rayleigh number in the case of a horizontal cell is larger than in the case of a vertical one (TGC). This allows performing separation in a larger cell. Bennacer et al. (2009) [6] suggested splitting a column filled with a porous media saturated by a binary fluid into three sub-domains.

In all the aforementioned works, two walls of the thermogravitational cell are maintained at constant and different temperatures while the two other walls are adiabatic. All the walls are impermeable. Bahloul et al. (2003) [7] studied the onset of Soret-driven convection in a shallow porous horizontal layer submitted to a vertical heat flux on the two horizontal walls. The thresholds for finite amplitude, oscillatory and monotonic convection instabilities are determined in term of the governing parameters of the problem. For their study, the authors used a closed-form analytical solution based on parallel flow approximation. However, they were not interested in the separation of the binary mixture components.

In the present article, we reconsidered the previous study with a focus on the species separation between the two horizontal ends of the cell, which appears after the transition from the rest flow to unicellular flow for low values of the Rayleigh number and for positive separation ratio. In the first part, an analytical solution was performed in the case of a shallow cavity (aspect ratio $A \gg 1$ ) and the separation was expressed in terms of thermal Rayleigh number, Lewis number, separation ratio and aspect ratio of the cell. The value of the Rayleigh number leading to the maximum separation was obtained analytically. The analytical results were corroborated by direct non-linear numerical simulations performed using a finite element method. Then a comparison between the separation obtained in this new configuration with the one obtained in TGC column was developed.

\section{Mathematical formulation}

We consider a rectangular cavity with a high aspect ratio $A=L / H$, where $H$ is the height of the cavity along the vertical axis $\vec{e}_{y}$ and $L$ is its width along the horizontal axis $\vec{e}_{x}$. The cavity is filled with a porous medium saturated by a viscous binary fluid mixture of density $\rho$ and dynamic viscosity $\mu$. The two horizontal walls $y=-H / 2$ and $y=+H / 2$ are subjected to a uniform heat flux, $q^{\prime}$ and are impermeable. The two vertical walls $x=-L / 2$ and $x=+L / 2$ are adiabatic and impermeable. All the boundaries are assumed to be rigid. We consider an isotropic and homogeneous porous medium. We assume that Darcy's law and the Boussinesq approximation are valid, thus the thermophysical properties of the binary fluid are constant except the density in the buoyancy term which varies linearly with the local temperature $T$ and the mass fraction $C$ of the denser component;

$$
\rho=\rho_{0}\left[1-\beta_{T}\left(T-T_{0}\right)-\beta_{C}\left(C-C_{0}\right)\right]
$$

where $\beta_{T}$ and $\beta_{c}$ are respectively the thermal and mass expansion coefficients of the binary fluid ( $T_{0}$ and $C_{0}$ correspond to the reference state). 
The dimensionless mathematical formulation of the problem is given by

$$
\left\{\begin{array}{l}
\nabla^{2} \psi=-R a\left(\frac{\partial T}{\partial x}+\varphi \frac{\partial C}{\partial x}\right) \\
\frac{\partial T}{\partial t}+u \frac{\partial T}{\partial x}+v \frac{\partial T}{\partial y}=\nabla^{2} T \\
\varepsilon \frac{\partial C}{\partial t}+u \frac{\partial C}{\partial x}+v \frac{\partial C}{\partial y}=\frac{1}{L e}\left(\nabla^{2} C-\nabla^{2} T\right)
\end{array}\right.
$$

The reference scales are $H$ for the length, $a / H$ for the velocity with $a=\lambda^{*} /(\rho c)_{f}$ ( $a$ is the effective thermal diffusivity of the porous-mixture system, $\lambda^{*}$ is the effective conductivity), $H^{2} \phi / a$ for the time (with $\phi=(\rho c)^{*} /(\rho c)_{f},(\rho c)^{*}$ and $(\rho c)_{f}$ are respectively the effective volumetric heat capacity and the volumetric heat capacity of the fluid), $\Delta T=q^{\prime} H / \lambda^{*}$ for the temperature, $\Delta C=-\Delta T C_{0}\left(1-C_{0}\right)\left(D_{T}^{*} / D^{*}\right)$ for the mass fraction, where $D_{T}^{*}$ and $D^{*}$ are respectively the thermodiffusion and mass-diffusion coefficients of the denser component. $\psi$ is the stream function. As usually the equation of continuity is satisfied by introducing the stream function according to: $u=\partial \psi / \partial y$ and $v=-\partial \psi / \partial x$. The problem under consideration depends on five non-dimensional parameters: the thermal Rayleigh number, $R a=\left(K g \beta_{T} H \Delta T(\rho c)_{f}\right) /\left(\lambda^{*} v\right)$, where $K$ is the permeability of porous medium and $g$ is the gravitational acceleration, the separation ratio $\varphi=-\left(\beta_{T} / \beta_{c}\right)\left(D_{T}^{*} / D^{*}\right) C_{i}\left(1-C_{i}\right)$ where $C_{i}$ is the initial mass fraction, the Lewis number $L e=a / D^{*}$, the normalized porosity, $\varepsilon=\varepsilon^{*} / \phi$ and the aspect ratio $A=L / H$.

The corresponding dimensionless boundary conditions are

$$
\begin{aligned}
& y=-\frac{1}{2}: \quad \psi=0, \quad \frac{\partial T}{\partial y}=\frac{\partial C}{\partial y}=-1 ; \quad y=\frac{1}{2}: \quad \psi=0, \quad \frac{\partial T}{\partial y}=\frac{\partial C}{\partial y}=-1 \\
& x=-\frac{A}{2}: \quad \psi=0, \quad \frac{\partial T}{\partial y}=\frac{\partial C}{\partial y}=0 ; \quad x=\frac{A}{2}: \quad \psi=0, \quad \frac{\partial T}{\partial y}=\frac{\partial C}{\partial y}=0
\end{aligned}
$$

\section{Analytical solution in the case of a shallow cavity}

\subsection{Closed-form analytical solution}

In the case of a shallow cavity $A \gg 1$, we consider the parallel flow approximation used by many authors (see for instance Mamou et al. [8]). The basic flow is given as follows:

$$
\psi(x, y)=\psi(y) ; \quad T(x, y)=b x+f(y) ; \quad C(x, y)=m x+g(y)
$$

where $b$ and $m$ are respectively the temperature and mass fraction gradients along the $x$ axis.

With these assumptions and for the steady state, the system of Eqs. (3) is reduced to a set of ordinary differential equations solved with Maple:

$$
\left\{\begin{array}{l}
\frac{\mathrm{d}^{2} \psi}{\mathrm{d} y^{2}}=-R a(b+\varphi m) \\
b \frac{\mathrm{d} \psi}{\mathrm{d} y}=\frac{\partial^{2} f}{\partial y^{2}} \\
m \frac{\mathrm{d} \psi}{\mathrm{d} y}=\frac{1}{L e}\left(g^{\prime \prime}-f^{\prime \prime}\right)
\end{array}\right.
$$

Using the boundary conditions (4) we obtain for the stream function the following expression:

$$
\psi=\psi_{0}\left(1-4 y^{2}\right) \quad \text { with } \quad \psi_{0}=\frac{1}{8} R a(b+\varphi m)
$$

and the expressions of $f(y)$ and $g(y)$ by integration:

$$
\begin{aligned}
& f(y)=-\frac{4}{3} \psi_{0} b y^{3}+\psi_{0} b y-y \\
& g(y)=-\frac{4}{3} \psi_{0} y^{3}(m L e+b)+\left(\psi_{0} m L e+\psi_{0} b-1\right) y
\end{aligned}
$$

In order to obtain the expression of $b$ and $m$ respectively, we use the fact that at the steady state, the total heat transfer through any cross section perpendicular to the $x$ axis and the mass flow of the component of mass fraction $C$ is zero, so:

$$
\int_{-1 / 2}^{1 / 2}(u(y) f(y)-b) \mathrm{d} y=0 \text { and } \int_{-1 / 2}^{1 / 2}(u(y) g(y) L e-m+b) \mathrm{d} y=0
$$






Fig. 1. Separation $S=m A$ versus Rayleigh number for $\varphi=0.4, L e=2,50,100$.

which leads to the expression of $b$ and $m$ :

$$
b=\frac{10 \psi_{0}}{8 \psi_{0}^{2}+15} \text { and } m=-\frac{8 L e \psi_{0}^{2} b-10 L e \psi_{0}-15 b}{8 L e^{2} \psi_{0}^{2}+15}
$$

By inserting $b$ and $m$ by their expression in Eq. (7), we obtain a 5 th order polynomial equation for $\psi_{0}$, which solutions are $\psi_{0}=0$ and

$$
\begin{aligned}
\psi_{0}= & \pm \frac{\sqrt{5}}{8} \frac{1}{L e}\left(R a L e^{2}-12-12 L e^{2}\right. \\
& \left. \pm \sqrt{R a^{2} L e^{4}+24 R a L e^{2}-24 R a L e^{4}+144-288 L e^{2}+144 L e^{4}+48 L e^{3} R a \varphi+48 L e^{2} R a \varphi}\right)^{1 / 2}
\end{aligned}
$$

In conclusion, the analytical solution in the case $A \gg 1$ is:

$$
\left\{\begin{array}{l}
\psi=\psi_{0}\left(1-4 y^{2}\right) \\
T=b x-\frac{4}{3} \psi_{0} b y^{3}+\psi_{0} b y-y \\
C=m x-\frac{4}{3} \psi_{0} y^{3}(m L e+b)+\left(\psi_{0} m L e+\psi_{0} b-1\right) y \\
\psi_{0}= \pm \frac{\sqrt{5}}{8} \frac{1}{L e}\left(R a L e^{2}-12-12 L e^{2}\right. \\
\quad \pm \sqrt{\left.R a^{2} L e^{4}+24 R a L e^{2}-24 R a L e^{4}+144-288 L e^{2}+144 L e^{4}+48 L e^{3} \operatorname{Ra\varphi }+48 L e^{2} \operatorname{Ra\varphi }\right)^{1 / 2}}
\end{array}\right.
$$

\subsection{Separation}

We study the species separation of the binary mixture between the two vertical ends of the horizontal porous cavity. The separation $S$ is defined as the difference of the mass fraction of the denser species between the two ends of the cell $(x=A / 2$ and $x=-A / 2)$ and its expression is $S=m A$

As indicated in Eqs. (11) and (12), $m$ and the separation $S$ are functions of the Lewis number $L e$ and $\psi_{0}=f(R a, L e, \varphi)$. We choose the set of parameters $L e=2,50,100$ and $\varphi=0.4$. The cases $L e=50,100$ correspond to liquid binary mixtures while the case $L e=2$ corresponds to gas binary mixture.

The vertical stratification of the mass fraction field is obtained at low Rayleigh numbers. The maximum separation is obtained for an optimal value of the Rayleigh number $R a_{\text {opth }}$.

For each value of $\varphi$, we can obtain the value of $R a_{o p t h}$ with the software Maple. So, for $\varphi=0.4$ and for $L e=2: R a_{o p t h}=$ 7.85, for $L e=50: R a_{\text {opth }}=1.07$ and for $L e=100: R a_{\text {opth }}=0.56$.

In Fig. 1 , the curves $S=f(R a)$ for $\varphi=0.4$ and $L e=2,50,100$ are plotted.

For $R a_{\text {opth }}$, the coupling between the two phenomena, thermodiffusion and convection, is optimal. If $R a$ is lower than $R a_{\text {opth }}$, the convection is weak and the separation is small, and when $R a$ is higher than $R a_{o p t h}$, the intensity of convection increases, so the separation decreases. One can note that for $L e=50$ and $L e=100$, the maximum separation is quite the same $S_{\max } \approx 4.6$, while for $L e=2, S_{\max } \approx 5.7$. 


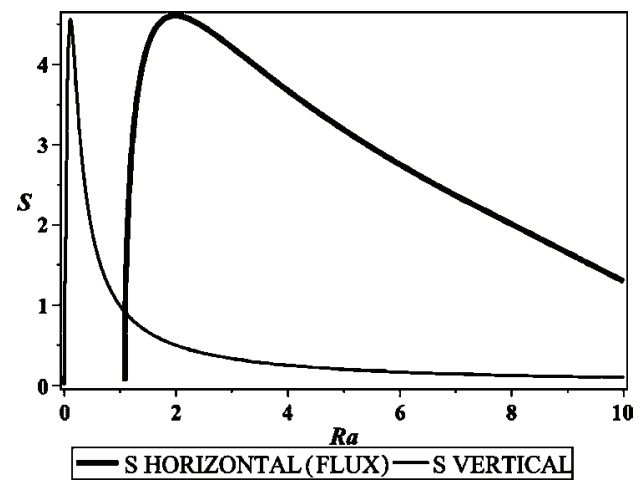

Fig. 2. Separation in horizontal and TGC cells for $L e=100, \varphi=0.1$

It will be noted that due to the reference scale used for the mass fraction, the separation $S$ may be higher than one. Using the Forgotten effect, i.e. the term $\varphi C$ in the Darcy's law is neglected, we can obtain an approximate relation which gives the following expression for $R a_{o p t h}$ :

$$
\begin{aligned}
R a_{o p t h}= & \frac{1}{L e^{2}\left(10 L e^{2}+197 L e-253\right)}\left(40 L e^{4}-2400 L e^{2}+2000 L e^{3}\right. \\
& \left.-400 L e+440+40 \sqrt{121-220 L e+1816 L e^{2}}\right)^{1 / 2}
\end{aligned}
$$

3.3. Comparison between the separation obtained in a thermogravitational column and in a horizontal layer submitted to constant heat flux

In order to show the advantage of the horizontal configuration submitted to heat flux, the separation obtained in this case is compared to the one obtained in the thermogravitational column.

Elhajjar et al. [5] studied the thermogravitation in a vertical column of height $H$ and thickness $e$. The vertical walls of the cell were kept at constant and different temperatures. To obtain an analytical solution in the case $A=H / e \gg 1$, the authors used the same assumptions than in Section 3.1. The term $\varphi C$ in the Darcy's law was neglected (Forgotten effect). Under these assumptions the separation is $S_{v}=m_{v} A$ with

$$
m_{v}=(10 L e R a) /\left(L e^{2} R a^{2}+120\right)
$$

Thus, the maximum separation is obtained for an optimum value of the Rayleigh number, $R a_{o p t v}=\sqrt{120} / L e$. For $L e=100$ and $\varphi=0.1$ (Fig. 2) the two curves $S=f(R a)$ are plotted in the case of the horizontal cell submitted to heat flux and in a TGC column, with the Rayleigh number based on $H$ for the horizontal cavity and the thickness $e$ for the TGC column so $R a_{H} / R a_{v}=\left(\Delta T_{H} / \Delta T_{v}\right)(H / e)$.

If we now compare the ratio of the optimal Rayleigh numbers in the two configurations, we obtain:

$$
\begin{aligned}
& r=R a_{\text {opth }} / R a_{\text {optv }} \\
& r=\frac{0.091287\left(40 L e^{4}-2400 L e^{2}+2000 L e^{3}-400 L e+440+40 \sqrt{121-220 L e+1816 L e^{2}}\right)}{L e\left(10 L e^{2}+197 L e-253\right)}
\end{aligned}
$$

So, for $L e=2, r=2.52$, for $L e=50, r=26.07$ and for $L e=100, r=45.67$.

In Fig. 2, we note that the maximum separation is quite the same in the two configurations, but $S_{v}$ decreases very quickly with $R a$ while the separation in the horizontal cell decreases softer, indicating that the separation can occur in a wider range of $R a$ and allows the use of greater height cells. In conclusion, for the same difference of temperature, in a horizontal cell with a height $H$ much higher than the width $e$ of a TGC column, the obtained separation is largest in the horizontal cell and the amount of separated species is higher. It is also easier to realize these cells experimentally. Indeed the width of the TGC column at the maximum separation is about a fraction of a mm.

\section{Numerical simulations}

The system of Eqs. (3) with the boundary conditions (4) are solved numerically using a finite element code (Comsol industrial code) with a rectangular grid, better suited to the rectangular configuration. For the computations, we consider an aspect ratio $A=10$. The spatial resolution is $120 \times 20$. 
Table 1

Analytical and numerical separation for $L e=100$ and $\varphi=0.4$

\begin{tabular}{llllll}
\hline$R a$ & $S$ analytical & $S$ numerical & $R a$ & $S$ analytical & $S$ numerical \\
\hline 0.3 & 1.6862 & 1.605 & 0.75 & 4.4540 & 4.454 \\
0.4 & 4.1492 & 4.149 & 1 & 4.1034 & 4.103 \\
0.5 & 4.5651 & 4.591 & 1.5 & 3.4886 & 3.488 \\
0.56 & 4.6092 & 4.640 & 2 & 3.0352 & 3.033 \\
0.6 & 4.6014 & 4.601 & 2.5 & 2.6903 & 2.690 \\
0.64 & 4.5754 & 4.575 & 4 & 1.9989 & 2.416 \\
0.68 & 4.5376 & 4.537 & 5 & 1.6855 & 1.999 \\
0.70 & 4.5155 & & & \\
\hline
\end{tabular}
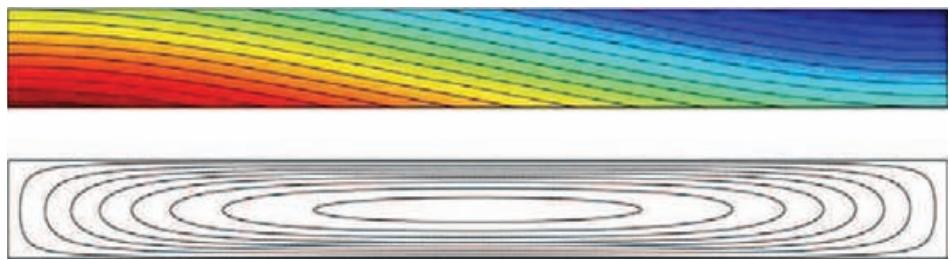

(a)
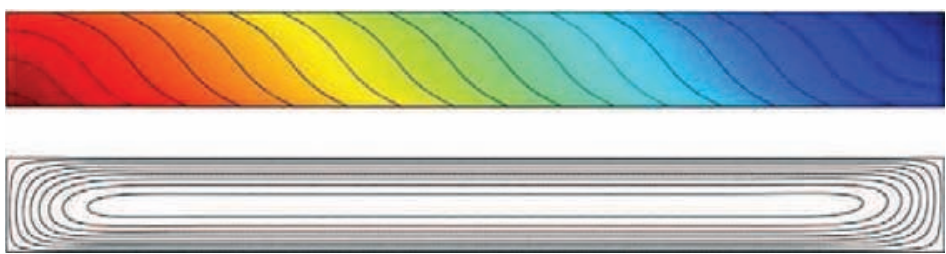

(b)
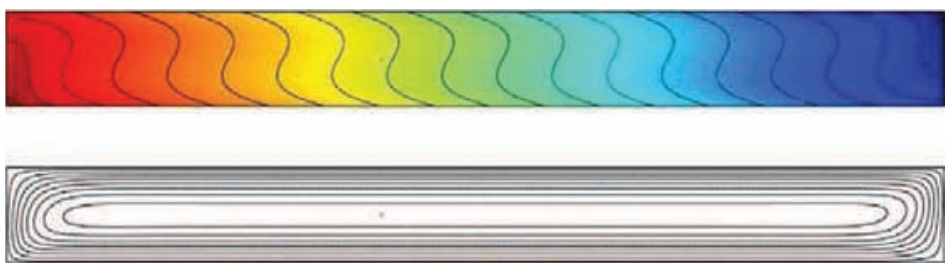

(c)

Fig. 3. Isoconcentrations and streamlines for (a) $R a=0.3, L e=100, \varphi=0.4$; (b) $R a_{o p t h}=0.56, L e=100, \varphi=0.4$; (c) $R a=2.5, L e=100, \varphi=0.4$.

In order to eliminate the effects due to the presence of the two vertical ends for calculating the separation, we plot the curve $C=f(x)$ at a given value of $y$ ( $y=0$, for instance) and we calculate the slope of the curve which is a straight line in the central part of the cell.

In Table 1 , we present the separations obtained numerically and analytically for $L e=100$ and $\varphi=0.4$. The results obtained numerically are in very good agreement with those obtained analytically. The same result is obtained for $L e=2$, $L e=50$ and $\varphi=0.4$.

For $L e=100$ and $\varphi=0.4$, Fig. 3 shows the mass fraction field and the streamlines for $R a=0.3, R a_{o p t h}=0.56$ and $R a=2.5$.

We can see in Figs. 3(a), 3(b), and 3(c) that for $R a=0.3$, the stratification of the mass fraction field is not vertical and that the assumption of parallel flow is only respected near the center of the cavity. For $R a=R a_{\text {opth }}$, the maximum separation is obtained: the assumption of parallel flow is respected except near the two vertical walls. As $R a$ increases from $R a_{o p t h}$, the convection increases as indicated by the deformation of the mass fraction field. Thus the separation decreases.

\section{Conclusion}

In this article, analytical and numerical studies were performed to investigate the separation in a horizontal porous layer saturated by a binary mixture and subjected to constant heat flux on the two horizontal walls. In the first part an analytical solution was determined in the case of a shallow cavity $(A \gg 1)$. The separation was calculated for different sets of values of $R a$, Le and the separation ratio, $\varphi$. The maximum separation was obtained for an optimal value of the Rayleigh 
number. The analytical results were corroborated by direct numerical simulations using a finite element code (Comsol). The comparison with the separation obtained in differentially heated vertical columns (TGC) showed that even if the maximum value of the separation is the same in both configurations, the use of horizontal cells submitted to heat flux allowed height higher than the width of TGC column, increasing the amount of separated species significantly.

\section{References}

[1] K. Clusius, G. Dickel, Neues Verfahren zur Gasenmischung und Isotroprennung, Naturwissenschaften 6 (1938) 546

[2] W.H. Furry, R.C. Jones, L. Onsager, On the theory of isotope separation by thermal diffusion, Phys. Rev. 55 (1939) 1083-1095.

[3] M. Lorenz, A.H. Emery, The packed thermal diffusion column, Chem. Eng. Sci. 11 (1) (1959) 16-23.

[4] J.K. Platten, M.M. Bou-Ali, J.F. Dutrieux, Enhanced molecular separation in inclined thermogravitational columns, J. Phys. Chem. B 107 (42) (2003) 11763-11767.

5] B. Elhajjar, M.C. Charrier-Mojtabi, A. Mojtabi, Separation of a binary fluid mixture in a porous horizontal cavity, Phys. Rev. E 77 (2008) 026310 (1-6 pp.)

[6] R. Bennacer, A.A. Mohamad, M. El Ganaoui, Thermodiffusion in porous media: Multi-domain constituent separation, Int. J. Heat Mass Transfer 52 (2009) 1725-1733.

[7] A. Bahloul, N. Boutana, P. Vasseur, Double-diffusive and Soret-induced convection in a shallow horizontal porous layer, J. Fluid Mech. 491 (2003) $325-$ 352

[8] M. Mamou, P. Vasseur, E. Bilgen, D. Gobin, Double-diffusive convection in an inclined slot filled with porous medium, Eur. J. Mech. B/Fluids 14 (1995) $629-652$ 